\title{
Ever-Green Revolution and Sustainable Food Security
}

\section{M.S. SWAMINATHAN}

M.S. Swaminathan Research Foundation

Chennai, India

The "green revolution," a term coined by William Gaud in October, 1968, is a process that leads to improved agricultural productivity. In January, 1968, in a lecture at the Indian Science Congress, I emphasized the need to improve productivity in perpetuity without associated ecological and/or social harm (Swaminathan, 1993):

Exploitive agriculture offers great dangers if carried out with only an immediate profit or production motive. The emerging exploitive farming community in India should become aware of this. Intensive cultivation of land without conservation of soil fertility and soil structure would lead, ultimately, to the springing up of deserts. Irrigation without arrangements for drainage would result in soils getting alkaline or saline. Indiscriminate use of pesticides, fungicides and herbicides could cause adverse changes in biological balance as well as lead to an increase in the incidence of cancer and other diseases, through the toxic residues present in the grains or other edible parts. Unscientific tapping of underground water will lead to the rapid exhaustion of this wonderful capital resource left to us through ages of natural farming. The rapid replacement of numerous locally adapted varieties with one or two high-yielding strains in large contiguous areas would result in the spread of serious diseases capable of wiping out entire crops, as happened prior to the Irish potato famine of 1854 and the Bengal rice famine in 1942. Therefore the initiation of exploitive agriculture without a proper understanding of the various consequences of every one of the changes introduced into traditional agriculture, and without first building up a proper scientific and training base to sustain it, may only lead us, in the long run, into an era of agricultural disaster rather than one of agricultural prosperity." 
Later, I coined the term "ever-green revolution" to highlight the pathway of increasing production and productivity in a manner such that short- and longterm goals of food production are not mutually antagonistic. In his recent book, The Future of Life (Vintage Books, 2002), Edward O. Wilson referred to my concept of ever-green revolution:

The problem before us is how to feed billions of new mouths over the next several decades and save the rest of life at the same time, without being trapped in a Faustian bargain that threatens freedom and security. No one knows the exact solution to this dilemma. The benefit must come from an evergreen revolution. The aim of this new thrust is to lift food production well above the level obtained by the green revolution of the 1960s, using technology and regulatory policies more advanced and even safer than those now in existence.

\section{How do we achieve this ever-green revolution, i.e. a balance between human numbers and human capacity to produce food of adequate quantity, quality and variety?}

How do we achieve this ever-green revolution, i.e. a balance between human numbers and human capacity to produce food of adequate quantity, quality and variety? The growing damage to the ecological foundations essential for sustainable food security_land, water, biodiversity, forests and the atmosphere-is leading to stagnation in yields in green-revolution areas. Climate change may compound such problems with adverse effects on temperature, precipitation, sea level and ultra-violet $\mathrm{B}$ radiation.

An analysis of food insecurity indicators in rural India carried out by the M.S. Swaminathan Research Foundation (MSSRF) with support from the World Food Programme (WFP), indicates that the Punjab-Haryana region-India's food basket-may become food-insecure in another 20 years. Indicators used in measuring sustainability of food security are: land degradation and salinization, extent of forest cover, groundwater depletion and the nature of crop rotation. In all of these parameters, Punjab and Haryana occupy low positions. The common rice-wheat rotation has led to displacement of grain and fodder legumes capable of improving soil fertility. The current trend is towards non-sustainable farming resulting from land and water mining.

Forewarned is forearmed. What can we do to launch global agriculture on the pathway to an ever-green revolution, where advances in crop and farm-animal productivity are not accompanied by either ecological or social harm? The following suggestions are aimed at converting the vast know-how now available into field-level do-how. 


\section{INTEGRATED ATtENTION TO THE COMPONENTS OF FOOD SECURITY}

Food security has three major dimensions:

- availability of food-a function of production,

- access to food-a function of purchasing power/access to sustainable livelihoods, and

- absorption of food in the body-determined by access to safe drinking water and non-food factors such as environmental hygiene, primary health care and primary education.

Capacity to support even the existing human and animal populations has been exceeded in many parts of the developing world. Hence, the future of food security depends upon population stabilization, the conservation and care of arable land through attention to soil health and replenishment of fertility, and the conservation and careful management of all water sources so that more crop can be produced per drop of water.

\section{OWNERSHIP AND SUSTAINABLE USE}

Much of the degraded and desertified land belongs either to resource-poor families or constitutes over-used and over-grazed common property. Ownership patterns of land and water determine the feasibility of introducing integrated and sustainable land- and water-management systems. Even where land is individually owned, locally acceptable systems of social management may have to be introduced through legislation, education and social mobilization. Women's access to land is also important. Water, particularly groundwater, should be a social resource and not private property. Creating an economic stake in conservation is vital for ensuring the sustainable use of natural resources.

\section{ENVIRONMENTAL REFUGEES}

Degradation and erosion of arable land and the depletion and pollution of water resources result in the loss of rural livelihoods. This triggers unplanned migration of the rural poor to towns and cities, with proliferation of urban slums. The rise in the numbers of such environmental refugees threatens peace and security. Norman Myers has chronicled the seriousness of the situation. There should be a monitoring mechanism for avoiding loss of rural livelihoods. Development programs should strengthen linkages between ecological and livelihood security.

\section{There are now unique opportunities for launching a food- for-sustainable-development initiative, in the form of a "grain for green" movement.}




\section{Grain MOUNTAINS AND Hungry Millions: THE GROWING PARADOX}

There are now unique opportunities for launching a food-for-sustainable-development initiative, in the form of a "grain for green" movement. Such a program could accord priority to:

- restoration of hydrological and biodiversity "hot spots," particularly in mountain ecosystems,

- coastal agro-aqua farms (planting of salicornia, mangroves, casuarina, palms, etc. along with coastal agriculture and aquaculture),

- water harvesting, watershed development, wasteland reclamation, and anti-desertification measures,

- recycling of solid and liquid wastes and composting, and

- agro-forestry and other sustainable land-use systems in the fields of resource-poor farmers.

A Global Food for Sustainable Development and Hunger Elimination Initiative could be launched by the International Alliance Against Hunger, proposed by FAO. About 25 million tonnes of grains would provide nearly 100 million person-years of work designed to eliminate poverty-induced endemic hunger and at the same time restore and enhance environmental capital stocks.

Such food-for-ecodevelopment initiatives could be managed at the local level by community food banks (CFBs) operated by women's self-help groups. Such CFBs can be designed to address concurrent issues relating to chronic, hidden and transient hunger. The merit of CFBs will be low transaction cost and transparency. They can also help to widen the food-security basket, thereby saving what could become "lost" crops. Where animal husbandry, including poultry farming, is important to provide additional income and nutrition to families living in poverty, CFBs could also operate feed and fodder banks.

It is the fundamental duty of the state as well as of the well-to-do sections of the population to confer on those who go to bed undernourished the right to food and thereby to opportunities to lead productive and healthy lives. Thanks both to the spread of democratic systems of governance at the grass-roots level and to technological advances, we now have a unique opportunity to foster a community-centered and controlled-nutrition security system. Such decentralized community management will help to improve delivery of entitlements, reduce transaction and transport costs, eliminate corruption and cater to the twin needs of introducing a life-cycle approach to nutrition security and meeting the challenge of seasonal fluctuation in nutritional status. If such CFBs are operated by women, this will help to bridge the gender divide in the area of nutrition.

\section{NEW GeNETICS}

The elucidation of the double-helical structure of the deoxyribonucleic acid (DNA) molecule in 1953 by James Watson, Francis Crick, Maurice Wilkins and Rosalind 
Franklin marked the beginning of what is now known as the "new genetics." Research during the past 51 years in the fields of molecular genetics and recombinant DNA technology has opened up new opportunities in agriculture, medicine, industry and environmental protection. The ability to move genes across species barriers has led to heightened interest in the conservation and sustainable and equitable use of biodiversity, since biodiversity is the feedstock for plant, animal and microbial breeding enterprises.

Considerable advances have been made in the past 25 years, taking advantage of the new genetics, in medical research, production of vaccines, sero-diagnostics and pharmaceuticals for human and farm-animal healthcare. The production of novel bioremediation agents—-for example, the new Pseudomonas strain for clearing oil spills in oceans, rivers and lakes developed by Anand Chakraborty-is also receiving priority attention because of increasing environmental pollution.

There has also been substantial progress in agriculture, particularly in crop improvement through molecular-marker-assisted breeding, functional genomics, and recombinant DNA technology. A wide range of crop varieties containing novel genetic combinations are now being cultivated in the United States, Canada, China, Argentina and several other countries. A cotton variety containing the Bacillus thuringiensis gene (Bt cotton), resistant to the bollworm, is now under cultivation in India resulting from official and unofficial (illegal) releases.

There is little doubt that the new genetics has opened up uncommon opportunities for enhancing the productivity, profitability, sustainability and stability of major cropping systems. It has also created scope for developing crop varieties tolerant/resistant to biotic and abiotic stresses through an appropriate blend of Mendelian and molecular breeding techniques. It has led to the possibility of undertaking anticipatory breeding to meet potential changes in temperature, precipitation and sea level as a result of global warming. There are new opportunities for fostering pre-breeding and farmer-participatory breeding methods in order to combine genetic efficiency with genetic diversity.

While the benefits are clear, there are also many risks when entering unknown and unexplored territory. Such risks relate to potential harm to the environment and to human and animal health. There are also equity and ownership issues in relation to biotechnological processes and products. The following are major questions and areas of concern to the public and to the policymaker.

- What is inherently wrong with the technology? Is the science itself safe, an example being the use of selectable marker genes conferring antibiotic or herbicide resistance?

- Who controls the technology? If the technology is largely in the hands of the private sector, the overriding motive behind the choice of research problems will be profit and not necessarily public good. If this happens, "orphans will remain orphans" with reference to choice of research priorities. Crops being cultivated in rainfed, marginal and fragile environmentswhich are crying out for scientific attention-may remain neglected. 
- Who will have access to the products? If the products arising from recombinant DNA technology are all covered by intellectual property rights (IPR), it will result in social exclusion and will lead to further enlargement of the rich-poor divide in villages.

- What are the major biosafety issues? There are serious concerns about the short- and long-term effects of genetically engineered organisms on the environment, biodiversity and on human and animal health.

\section{There is need for transparent and truthful risk-benefit analyses in relation to genetically engineered organisms, on a case-by-case basis.}

Thus, there is need for transparent and truthful risk-benefit analyses in relation to genetically engineered organisms, on a case-by-case basis. In the coming decades, Indian farm women and men will have to produce more food and other agricultural commodities to meet home needs and to take advantage of export opportunities, under conditions of diminishing per capita availability of arable land and irrigation water and expanding abiotic and biotic stresses. Enlargement of the gene-pool with which breeders work will be necessary to meet these challenges. Recombinant DNA technology provides breeders with a powerful tool for enlarging the genetic base of crop varieties and for "pyramiding" genes for a wide range of economically important traits. The safe and responsible use of biotechnology will enlarge our capacity to meet the challenges ahead, including those caused by climate change. At the international level, the Cartagena Protocol on Biosafety provides a framework for risk assessment and aversion. At the national level, there is need for regulatory mechanisms that inspire public, political and professional confidence.

\section{SCIENCE AND ORGANIC SEED}

To ensure that organic farming leads to higher productivity per unit of land and water used, it is essential that research in the following areas is intensified.

\section{Soil-Health Management}

The earlier methods of soil-fertility management, like shifting cultivation, are no longer relevant today due to population pressure on land. Cereal-legume rotations and intercropping are important for replenishing soil fertility. Efficient green-manure plants like the stem-nodulating Sesbania rostrata and bio-fertilizers comprising efficient microorganisms (Higa, 1998) have to be packaged in an integrated nutrient-supply system, which includes the application of compost, organic manures and plant residues. Inputs are needed to ensure outputs. For example, a ton of rice needs at least $20 \mathrm{~kg}$ of nitrogen along with appropriate quantities of 
phosphorus, potassium and micronutrients. Research on soil-health management, in order to ensure adequate soil fertility for high productivity, should receive high priority. The efficient-microorganism (EM) methodology of Dr. Higa needs greater emphasis.

All organic farmers should be provided with soil health cards to monitor regularly the physics, chemistry, microbiology and erodability of their soils. Care of soil health is fundamental to productive agriculture.

Sustainable organic farming will also need bioremediation agents that can help to improve soil health through the sequestration of salt, heavy metals and other yield-reducing constraints. A consortium of microorganisms each capable of performing an important function like nitrogen fixation, phosphorus solubilization, and/or sequestration of salts and pollutants will be needed for each major agroclimatic and agro-ecological farming system.

The other area of research that is essential for sustained high productivity is integrated pest management involving concurrent attention to pests, diseases and weeds. For this purpose, there is need for a biosecurity compact that will help to manage not only pests, diseases and weeds, but also invasive alien species and mycotoxins in food. Sanitary and phytosanitary measures and Codex Alimentarius standards of food safety need to be integrated in organic production protocols.

\section{There will be need for productive genotypes of crop plants that can perform well under conditions of soil salinity, alkalinity and acidity.}

As population pressure on land and water increases, there will be need for productive genotypes of crop plants that can perform well under conditions of soil salinity, alkalinity and acidity. Special genetic gardens will have to be established for halophytes and drought-tolerant genotypes. Also, suitable donors for tolerance of salinity and drought will have to be used in anticipatory breeding for adaptation to climate change and sea-level rise. Scientists at MSSRF have developed sea-water tolerant genotypes of rice, mustard and legumes using the mangrove species Avicennia marina as donor. Similarly, Prosopis juliflora is being used as a donor of genes for drought tolerance. Such pre-breeding work needs to be integrated with participatory breeding with farm women and men so that location-specific varieties can be developed. Genetic diversity is essential to avoid vulnerability to pests and diseases. Therefore, gene-deployment strategies will have to be developed jointly by scientists and farm families for each agro-ecological region. Successful organic agriculture will need a paradigm shift from purely experiment-station-based research to participatory research in farmers' fields.

Teruo Higa's complex culture of naturally occurring beneficial microorganismsphotosynthetic bacteria, lactic acid bacteria, yeasts, fermentative fungi and 
actinomycetes-has multiple uses. It can be used to purify water and sewage, solve sanitary problems, and improve the environment. There is need for more research on such consortia of microorganisms.

Recent research at MSSRF by Loganathan and Nair has led to the isolation of a bacterial strain capable of fixing nitrogen and solubilizing phosphate. Swaminathania salitolerans gen. nov., sp. nov. was isolated from the rhizosphere, roots and stems of salt-tolerant wild rice associated with mangrove species. Field trials in rice using this microorganism are now in progress.

\section{It is important to harness all the tools that traditional wisdom and contemporary science can offer in order} to usher in an era of bio-happiness. The first requirement

$$
\begin{aligned}
& \text { for bio-happiness is nutrition and water security } \\
& \text { for all and forever. }
\end{aligned}
$$

Sustainable organic agriculture will need more science, not less. Artificial barriers should not be created between scientific methods. It is important to harness all the tools that traditional wisdom and contemporary science can offer in order to usher in an era of bio-happiness. The first requirement for bio-happiness is nutrition and water security for all and forever. This is the challenge before all involved in organic farming and the seed industry.

The seed industry has a particularly vital role to play in ensuring genetic diversity in crop plants and in providing organic farmers with genotypes based on a pyramiding of genes for tolerance to major biotic and abiotic stresses. There is also need for greater attention to under-utilized or orphan crops, many of which are not only nutritious but also capable of performing well under fragile and rainfed environments.

In order to change the mindset relating to nutritious millets, the Food and Agriculture Organization (FAO) should change the terminology from "coarse cereals" to "nutritious cereals." There is need to reverse the narrowing of global food crops by including in the diet a wider range of cereals, millets, grain legumes, vegetables and tubers. In the past, human communities depended upon several hundred species of plants for their nutrition and health security. Diversified farming systems and good dietary habits are essential to confer benefits both to the producer and to the consumer of organic farming products.

Production agriculture and forestry are the major solar-energy harvesting enterprises of the world. An ever-green revolution will help to optimize the production of farm commodities through a symbiotic interaction between solar and cultural energy. This is the pathway to sustainable food security and bio-happiness. 


\section{The rich-poor divide is widening and jobless economic growth-better described as joyless growth-is spreading. Although skin-color-based apartheid has ended, techno- logical and economic apartheids are appearing.}

\section{FINDING COMMON INTERNATIONAL GOALS: Patents AND UN MillenNiUm DeVElopMent GoAlS}

From the beginning of time, science and technology have been key elements in the growth and development of societies. Entire eras have been named for the levels of their technological sophistication: the stone age, the bronze age, the iron age, the age of sail, the age of steam, the jet age, the computer age and the age of genomics and proteomics. We are now on the threshold of the nano-age. Unfortunately, the scientific revolution is taking place at a faster pace than our social evolution. As a result, demographic, digital, gender, genetic, technological and economic divides are growing. The rich-poor divide is widening and jobless economic growth-better described as joyless growth—is spreading. Although skin-color-based apartheid has ended, technological and economic apartheids are appearing.

Since its inception, the United Nations University (UNU) has been a center for both humanistic science and scientific humanism. It has, therefore, a moral responsibility for showing how we can bridge these various divides and foster unity wherever discord prevails. The UNU should instil pride in performance and excellence. The UNU Institute for New Technologies (INTECH) should promote a global ecotechnology movement based on a blend of frontier science and traditional ecological prudence.

The world is facing a trilemma-a triple dilemma. Over 3 billion women and men, struggling to survive with an income of less than US\$2 per capita per day, are crying for peace and equitable economic development. Countries in southern Africa, and Ethiopia, Afghanistan and North Korea are in the midst of serious famines. In India, the severe debt burden of small farmers sometime results in suicides. Two thousand years ago, the Roman philosopher Seneca said, "A hungry person listens neither to reason nor religion, nor is bent by any prayer." Thus, one aspect of the trilemma is the craving for peace and development which is equitable in social and gender terms. On another side, there is a growing violence in the human heart. Terms like ethnic cleansing and biological and biochemical terrorism are widely used in the media. The revival of small pox is becoming a possibility. The nuclear peril has again raised its head. Over 30,000 nuclear weapons are stored in the arsenals of major and minor powers. The availability of large 
quantities of highly enriched uranium increases opportunities for nuclear adventurism.

The third side of the trilemma is the spectacular progress of science and technology, resulting in an increasing technological divide between industrialized and developing countries. Helping to bridge this divide can be an important contribution of advanced educational and research institutions like the University of Guelph.

In the 1994 report of the International Commission on Peace and Food, which I chaired, we anticipated a substantial peace dividend following the collapse of the Berlin wall and the end of the Cold War. No peace dividend has materialized, instead expenditure on military hardware and internal security is increasing day by day, particularly so as a result of the tragic events of September 11, 2001, in the United States and similar events elsewhere.

Contemporary developmental challenges, particularly those relating to poverty, gender injustice and environmental degradation are indeed formidable. However, remarkable advances in information and communication technology, space and nuclear technologies, biotechnology, agricultural and medical sciences, and renewable energy and clean-energy technologies provide hope for a better common present and future. Genomics, proteomics, the Internet, space and solar technologies and nanotechnology are opening uncommon opportunities for converting the goals of food, health, literacy and work for all into reality. It is however clear that such uncommon opportunities can be realized only if the technology push is matched by an ethical pull. This is essential for working towards a world in which unsustainable life styles and unacceptable poverty become features of the past.

\section{There is a growing mismatch between the rate of progress in science, particularly in molecular biology and genetic engineering, and the public understanding of their short- and long-term implications.}

Also, there is a growing mismatch between the rate of progress in science, particularly in molecular biology and genetic engineering, and the public understanding of their short- and long-term implications. There is an urgent need for institutional structures that inspire public confidence that risks and benefits are being measured in an objective and transparent manner. Scientists and technologists have a particularly vital role to play in launching an ethical revolution. The Pugwash movement, which I now have the privilege to head, is an expression of the social and moral duties of scientists to promote the beneficial applications 
of their work and prevent their misuse, to anticipate and evaluate possible unintended consequences of scientific and technological development, and to promote debate and reflection on the ethical obligations of scientists in taking responsibility for their work. Rabelais said, "Science is but the conscience of the soul." It is the enduring task of our universities, which are the breeding grounds of leaders who will shape our future, to ensure that science and technology are employed for the benefit of humankind, and not its destruction.

We now have a Global Convention on Biological Diversity to help in the conservation and sustainable and equitable use of biodiversity. We need urgently a similar Convention on Human Diversity. While a convention alone will not halt the growing intolerance of diversity-particularly with reference to religion and political belief-it will help foster a mindset that regards diversity as a blessing and not a curse. Both biodiversity and human diversity are essential for a sustainable future. The human genome map shows that over $99.9 \%$ of the genomic constitution is the same in all members of the human family. Universities should do more to spread genetic literacy.

It is also necessary to reflect on methods of giving meaning and content to the ethical obligations of scientists in relation to society. The 1999 World Conference on Science in Budapest called for a new social contract between scientists and society. With a rapidly expanding IPR atmosphere in scientific laboratories, the products of scientific inventions may become increasingly exclusive in relation to their availability, with access limited to those who can afford to pay. The rich-poor divide will then increase, since orphans will remain orphans with reference to scientific attention and investment. How can we develop a knowledge-management system that will ensure that inventions and innovations of importance to human health, food, livelihood and ecological security benefit every child, woman and man, and not just the wealthy? UNESCO could organize a Global Patents Bank for UN Millennium Development Goals. Scientists and technologists from all universities and public research institutions should be encouraged to assign their patents to such a bank, so that the fruits of scientific discoveries are available for the public good. Such a Patents Bank for UN Millennium Development Goals would stimulate scientists to consider themselves as trustees of their intellectual property, sharing their inventions with the poor in whose lives they may make a significant difference for the better. Over two centuries ago, the French mathematician the Marquis de Condorcet, a contemporary of Thomas Malthus, said that the human population will stabilize if children are born for happiness and not just existence. The Government of Bhutan has taken the lead in developing a Gross National Happiness Index, based on the economics of human dignity, love of art and culture and commitment to spiritual values. Making all well-to-do members of the human family regard themselves as trustees of their financial and intellectual property will be essential for fostering a human happiness movement. The twenty-first century holds great promise for advancing the human condition provided there is an appropriate blend of technology and public action. 


\section{RUSSELL AND EINSTEIN}

I will end with an appeal issued by Bertrand Russell, Albert Einstein and colleagues contained in the Russell-Einstein Manifesto (Born et al., 1955):

We appeal, as human beings, to human beings. Remember your humanity and forget the rest. If you can do so, the way is open to a new paradise; if you cannot, there lies before you the risk of universal death.

The year 2005 marks the sixtieth anniversary of the use of atom bombs on Hiroshima and Nagasaki and the fiftieth anniversary of the Russell-Einstein manifesto. Can we use this opportunity to rid humankind of the nuclear peril and concentrate on harnessing science and technology for achieving the goals of food, water, health and work for all and forever?

\section{REFERENCES}

Born N et al. (1955) The Russell-Einstein Manifesto. http://www.pugwash.org/ about/manifesto.htm.

Higa T (1998) An Earth Saving Revolution II. Tokyo: Sunmark Publishing Inc. Swaminathan MS (Ed.) (1993) Wheat Revolution : A Dialogue. Madras: Macmillan India Ltd.

74 Agricultural Biotechnology: Finding Common International Goals 


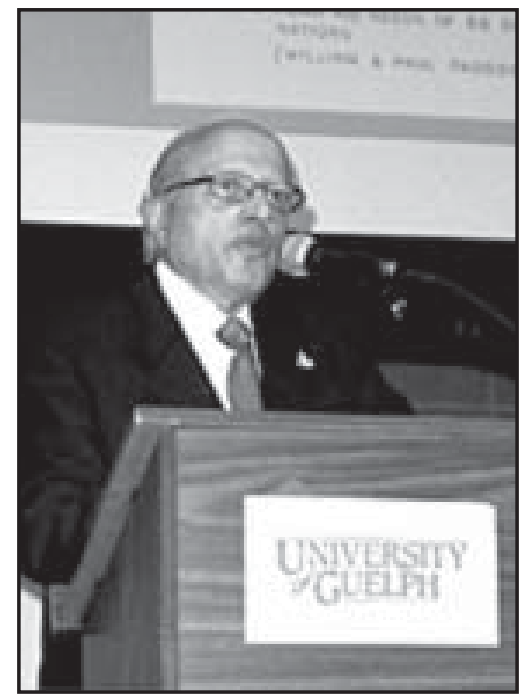

M.S. SWAMinathan has been acclaimed by Time magazine as one of the twenty most influential Asians of the twentieth century and one of only three from India, the others being Mahatma Gandhi and Rabindranath Tagore. He was described by the United Nations Environment Programme as "the father of economic ecology" and by Javier Perez de Cuellar, Secretary General of the United Nations, as "a living legend who will go into the annals of history as a world scientist of rare distinction."

A plant geneticist by training, Professor Swaminathan's contributions to the agricultural renaissance of India have led to his being widely referred to as the scientific leader of the green revolution movement. His advocacy of sustainable agriculture leading to an ever-green revolution makes him an acknowledged world leader in the field of sustainable food security.

Swaminathan is a fellow of many of the leading scientific academies of India and the world, including the Royal Society of London and the US National Academy of Sciences. He has received forty-five honorary doctorate degrees from universities around the world. He currently holds the UNESCO Chair in Ecotechnology at the MS Swaminathan Research Foundation in Chennai (Madras), India, and is chairman of the Pugwash Conferences on Science and World Affairs. 